\title{
Modeling a Decision Support Tool for Buildable and Sustainable Building Envelope Designs
}

\section{Natee Singhaputtangkul ${ }^{1, *}$ and Sui Pheng Low ${ }^{2}$}

1 School of Engineering and Technology, Central Queensland University, Sydney, NSW 2000, Australia

2 Department of Building, School of Design and Environment, National University of Singapore, 4 Architecture Drive, Singapore 117566, Singapore; E-Mail: bdglowsp@nus.edu.sg

* Author to whom correspondence should be addressed; E-Mail: n.singhaputtangkul@cqu.edu.au; Tel.: +61-45-143-0792.

Academic Editor: Fitsum Tariku

Received: 22 April 2015 / Accepted: 13 May 2015 / Published: 19 May 2015

\begin{abstract}
Sustainability and buildability requirements in building envelope design have significantly gained more importance nowadays, yet there is a lack of an appropriate decision support system (DSS) that can help a building design team to incorporate these requirements and manage their tradeoffs at once. The main objective of this study is to build such a tool to facilitate a building design team to take into account sustainability and buildability criteria for assessment of building envelopes of high-rise residential buildings in Singapore. Literature reviews were conducted to investigate a comprehensive set of the sustainability and buildability criteria. This also included development of the tool using a Quality Functional Deployment (QFD) approach combined with fuzzy set theory. A building design team was engaged to test the tool with the aim to evaluate usefulness of the tool in managing the tradeoffs among the sustainability and buildability criteria. The results from a qualitative data analysis suggested that the tool allowed the design team to effectively find a balance between the tradeoffs among the criteria when assessing multiple building envelope design alternatives. Main contributions of using this tool are achievement of a more efficient assessment of the building envelopes and more sustainable and buildable building envelope design.
\end{abstract}

Keywords: building envelope materials and designs; decision support system; quality function deployment; fuzzy set theory; high-rise residential buildings 


\section{Introduction}

Building envelope systems, as the interface between interior space and exterior environment, generally serve the function of weather and pollution exclusion and thermal and sound insulation [1]. Their performance affects, for example, occupant comfort and productivity, energy use, strength, durability, fire resistance, and aesthetics appeal of a building [2,3]. Building envelopes have played an important role the success of private high-rise residential building projects, and this highlights the importance of assessment and selection of the building envelope materials and designs that can satisfy project requirements. The project requirements can be referred to as criteria for achieving sustainability and buildability in building envelope design. In brief, sustainability is a balance of social and economic activities and the environment [4], while buildability points to an ability to construct a building efficiently, economically and to agreed quality levels using its construction resources [5].

Each country may have different guidelines and legal responsibilities for sustainability and buildability in building design. In Singapore, sustainability and buildability regulations have been in place for several years [6,7]. However, it was found that these regulations do not cover all key project requirements [8]. Fundamentally, a design team can easily find the design solutions that meet minimum needs of the regulations if the team does not have to incorporate other key sustainability and buildability criteria that could affect their designs such as durability of materials, aesthetics, costs and so on [9]. Nevertheless, in practice, it is difficult to develop an optimal sustainable and buildable design that takes into account all key criteria without effective management of their tradeoffs [10]. This leads to a main research problem of this study, which is an absence of a decision support tool that can enable the designers in Singapore to assess building envelope designs based on all the sustainability and buildability criteria at once and to effectively manage the tradeoffs among such criteria.

This study therefore develops a new and robust decision support system (DSS) to fill this gap. The study applies a Quality Function Deployment (QFD) approach and fuzzy set theory to build the tool. This tool is known as a fuzzy QFD tool. The study begins by conducting literature reviews to identify a comprehensive set of the sustainability and buildability criteria for assessment of the building envelopes. This is followed by development of the fuzzy QFD tool embedded with a set of the identified criteria. The study then conducts a series of semi-structured interviews with 15 architects and engineers in Singapore in parallel with thorough literature reviews to acquire relevant knowledge for the tool and to fine-tune/validate the tool. The primary feedback from the interviews of these 15 architects and engineers is applied to adjust a decision-making process of the tool towards the achievement of more practical applications. This adjustment resulted in a more user-friendly tool being achieved.

A design team consisting of an architect, civil \& structural (C\&S) engineer, and mechanical and electrical (M\&E) are then engaged to test this tool as part of a case study. The team is given a representative high-rise residential project with a task to use the tool to select a building envelope system for this project. After the exercise is completed, the study conducts semi-structured interviews to collect perspectives of the team members regarding effectiveness of using the tool for incorporating the criteria and managing their tradeoffs. The interview results from the case study are then analyzed qualitatively. 


\section{Sustainability and Buildablity}

Sustainable development or sustainability is the fundamental principle underlying various efforts to ensure a decent quality of life for future generations. This concept aims to meet the needs of the present without compromising the ability of future generations to meet their needs. This implies that the environment and the quality of human life are as important as economic performance [1]. It was agreed that the mainstay of sustainability thinking is to strike a balance between three dimensions: environmental, social and economic impacts of the design. In the construction industry, awareness of sustainability among building professionals has increased [4]. This can be seen where the green market has been promoted to bring major improvements through developing green buildings, or where implementation of an energy rating guideline to assess environmental and energy performance of buildings has become more important. Benefits of adopting this concept in the construction industry include minimizing operating and maintenance costs, minimizing construction wastes, increasing occupant health and satisfaction, and so on [11,12].

Notwithstanding the concept of sustainability, buildability or constructability of a building also plays an important role in building design and construction. Buildability is widely accepted to be defined as the extent to which the design of a building facilitates ease of construction, subject to the overall requirements for the completed building [13]. Buildability takes into account all aspects of a building project, and enables the optimum utilization of construction resources. Several factors have been proposed over the years for achieving good buildability such as simplicity of design details, ease in material handling, ease in construction, etc. Benefits of buildability include lower costs of bidding, reduced site labor, increased cost effectiveness, and better resource utilization [14,15]. It was suggested that the design stage is critical for implementing buildability [16,17].

This study conducted extensive literature reviews to compile the comprehensive list of the sustainability and buildability criteria and this is shown in Table 1 . These criteria are divided into sustainability and buildability categories. The sustainability category is also made up of three subcategories which are environmental impact, economic impact and social impact.

Table 1. Sustainability and buildability criteria for building envelope design.

\begin{tabular}{|c|c|c|c|}
\hline \multicolumn{3}{|c|}{ Sustainability and buildability criteria } & \multirow{4}{*}{\begin{tabular}{l}
\multicolumn{1}{c}{ Selected references } \\
Bryan [18], Scheuer et al. $[19]$ \\
Chen et al. [20], Tsai et al. [21] \\
Jaillon and Poon [22], Tsai et al. [21]
\end{tabular}} \\
\hline \multirow{13}{*}{ Sustainability } & & EN1: Energy consumption & \\
\hline & Environmental & EN2: Resource consumption & \\
\hline & & EN3: Waste generation & \\
\hline & & EC1: Initial costs & Chua and Chou [3], Wang et al. [23] \\
\hline & Economic impact & EC2: Long-term burdens & Das et al. [24], Lacasse et al. [25] \\
\hline & & EC3: Durability & Bryan [18], Kneifel [26] \\
\hline & & SC1: Energy efficiency & Chua and Chou [3], Kibert [1] \\
\hline & & SC2: Appearance demands & Kaklauskas et al. [27], Yang et al. [10] \\
\hline & & SC3: Health, safety and security of & Brock [28], Chew [2], Yu and Kim [29] \\
\hline & Social impact & occupants and society & \\
\hline & & SC4: Weather protection performance & Bryan [18], Yang et al. [10] \\
\hline & & SC5: Acoustic protection performance & Low et al. [15], Yang et al. [10] \\
\hline & & SC6: Visual performance & Low et al. [30], Nielsen [31] \\
\hline
\end{tabular}


Table 1. Cont.

\begin{tabular}{lll}
\hline Sustainability and buildability criteria & \multicolumn{1}{c}{ Selected references } \\
\hline BC1: Health and safety of workers & Chen et al. [20], Hinze et al. [32] \\
BC2: Community disturbance & Chew [2], Kibert [1] \\
BC3: Simplicity of design details & Bryan [18], Yang et al. [10] \\
BC4: Material handling & Chew [2], Gould [33] \\
BC5: Ease in construction with respect to time & Chen et al. [20], Low et al. [15] \\
BC6: Material deliveries from suppliers & Gould [33], Vrijhoef and Kisela [34] \\
\hline
\end{tabular}

\section{Quality Functional Deployment (QFD)}

QFD has been found useful in making decisions of organizations. QFD aims at satisfying customer needs and expectations, which are considered utmost importance for the organizations. Many companies have adopted a QFD approach to improve quality of their products to satisfy their customers $[35,36]$. This is also obvious in the building industry. As a building project is relatively unique in the sense that each building is tailor-made to meet the requirements and needs of the customers that refer to all stakeholders of a project, using a QFD approach seems to make good sense [37]. In brief, QFD links the customers' requirements to engineering characteristics. A conventional QFD tool controls quality of the project through its House of Quality (HOQ), which contains rooms to achieve targets of the project $[35,36]$.

\section{Development of a Fuzzy QFD Tool}

Granted that QFD has been considered to be one of the most effective tools in facilitating group decision-making and suggesting optimal solutions, this study therefore taps into and, at the same time, expands this capability of a conventional QFD tool to build a more advanced QFD tool. In this regard, the convention HOQ was applied and modified to build an HOQ for Sustainability and Buildabilty (HOQSB) for the assessment of the building envelopes in this study. This HOQSB as shown in Figure 1 has five major rooms which are criteria for sustainability and buildability room (CR), building envelope materials and designs room (MR), relationships between the criteria and materials and designs room (RR), fuzzy inference engine for prioritizing design alternatives room (FR), and preference list room (PR). The CR storing the identified list of the sustainability and buildability criteria assists the Decision Makers (DMs) to identify the criteria for the assessment of the building envelopes, while the MR facilitates selection of the building envelope materials and designs. The RR contains the relationships between the criteria and design alternatives. These relationships include a matrix to indicate the parameters affecting each criterion and rules to guide the DMs when making the assessment decisions. The FR stores fuzzy calculation techniques operated by a fuzzy inference engine for making the tradeoffs between the criteria and fine-tuning the design alternatives. The PR records outputs of the FR in the form of a preference list of the design alternatives ranked by a Sustainability and Buildability Index (SBI). This index is a function of importance weights of the criteria and performance satisfactions of the design alternatives with respect to the criteria. This study then modeled the tool using Microsoft Visual Studio. 


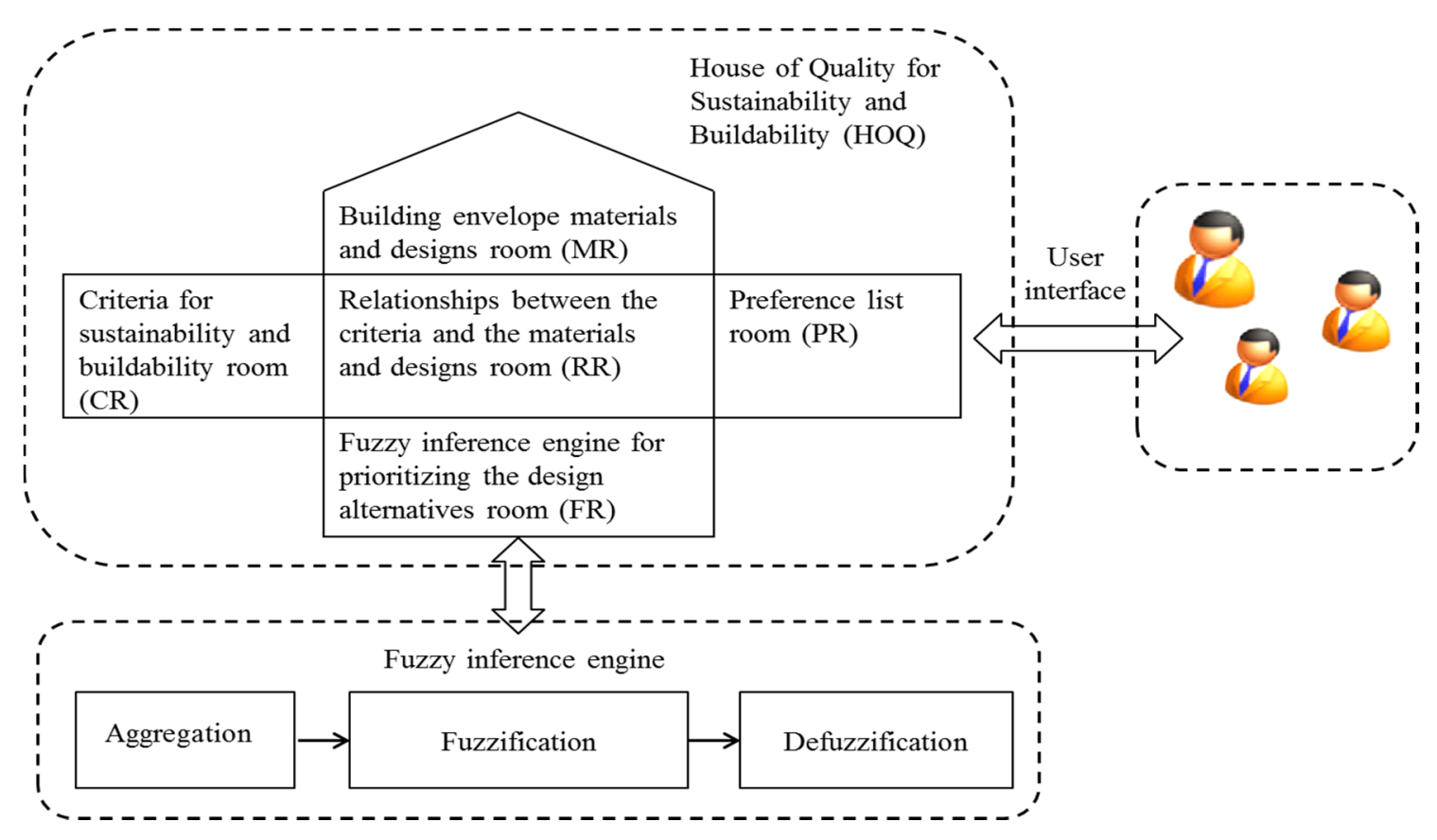

Figure 1. House of Quality for Sustainability and Buildabilty (HOQSB).

\subsection{Fuzzy Inference Engine}

In a real-world decision situation, making decisions has to process not only large amount of information but also subjective and uncertain requirements [38]. Particularly, DMs may encounter practical constraints from several criteria usually containing imprecision, subjective or vagueness inherent in the information [39]. It was suggested that the fuzzy set theory introduced by Zadeh [40] could mitigate this problem by translating subjective information, incomplete information and partially ignorant facts into the decision model. Hence, the study adopted the fuzzy set theory to build the fuzzy QFD tool, and this was embedded as part of the FR.

\subsection{Fuzzy Linguistic Terms}

The triangular fuzzy numbers and their fuzzy linguistic terms were used in this study as shown in the screenshot given in Figure 2 for assessment of importance weights of the sustainability criteria and performance satisfactions of the building envelope designs [39]. Specifically, the DMs determine the tradeoffs among the criteria through the use of these different fuzzy linguistic terms. Calculation examples of fuzzy operations can be found in Bayrak et al. [41] and Yang et al. [10].

Based on the HOQSB and fuzzy inference engine developed, this study formed a five-step decision making process for the DMs to provide their inputs through a user interface of the tool as follows:

Step 1: Input project relevant information, and set up the triangular fuzzy linguistic terms.

Step 2: Select the criteria for the assessment based on the CR.

Step 3: Assess the importance weights of all the criteria selected.

Step 4: Select the building envelope materials to form the design alternatives based on the MR.

Step 5: Assess the performance satisfactions of the design alternatives with respect to the selected criteria through the RR. 
The FR embedded with the fuzzy inference engine then calculates the SBI and presents this through the PR.

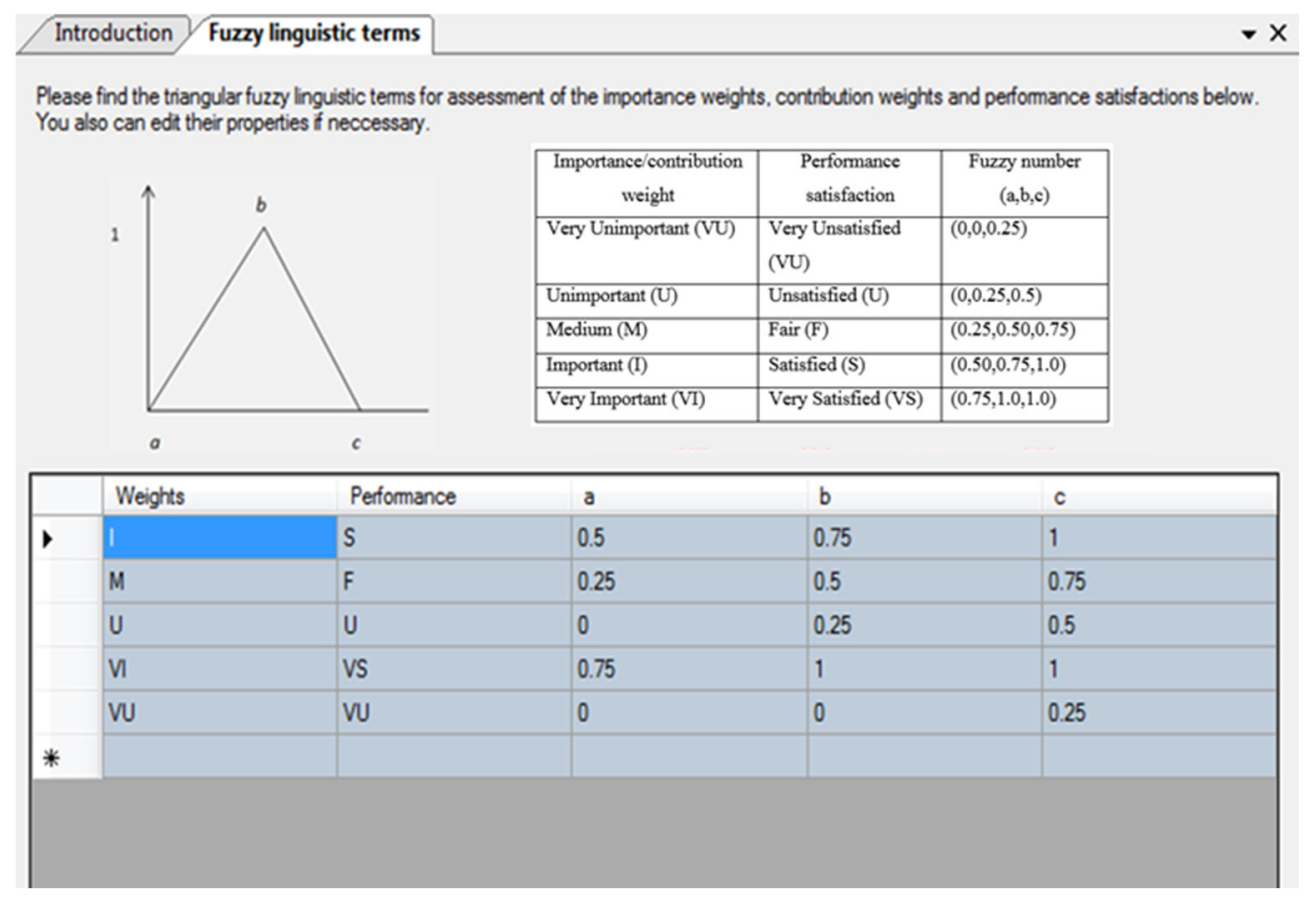

Figure 2. Fuzzy linguistic terms.

\section{Case Study}

This study employed a case study as a research design. This is because the case study approach meets the aim of this study, which is to investigate in-depth understanding of how the fuzzy QFD tool influences the decision-making process when the building design team assesses the building envelopes and the assessment outcomes. A case study tells a big story even if this is through the lens of a small case. This approach offers a close collaboration between researchers and participants, while enabling the participants to share their underlying perspectives [42]. Through this approach, the participants are able to express their views of reality, so much so that this allows the researcher to better understand the participants' actions and perspectives $[42,43]$.

A hypothetical design team was engaged in the case study to determine a conceptual design of the building envelopes for a representative private high-rise residential building project. This design team consists of three DMs; namely architect (DM1), C\&S engineer (DM2) and M\&E engineer (DM3). The project general information and criteria preliminarily identified by the architect were given in Tables 2 and 3, respectively. For simplicity, the project criteria do not cover all the identified sustainability and buildability criteria. A main task of the team was to propose a building envelope system of this project to the developer by using the tool through its five-step decision making process to assess potential alternatives. 
Table 2. General project information.

\begin{tabular}{cc}
\hline Developer & Condominium developer \\
\hline Project title & High-rise residential building B \\
Contract type & Design-Bid-Build \\
Project location & Jurong East \\
Preferred external wall material & Precast/concrete block/claybrick \\
Orientation/Plan configuration & North-South/Square \\
WWR & 0.3 \\
Height & $90 \mathrm{~m}$ \\
Floor-to-floor & $3 \mathrm{~m}$ \\
Area per floor & $400 \mathrm{~m}^{2}$ \\
Design and construction period & $28 \mathrm{months}$ \\
\hline
\end{tabular}

Table 3. Project key criteria.

\begin{tabular}{|c|c|c|}
\hline Criteria category & Criteria name & Brief description \\
\hline \multirow{3}{*}{ Environmental } & EN1: Energy consumption & $\begin{array}{l}\text { The building envelope material and design must minimize } \\
\text { consumption of electricity and fuel during construction. }\end{array}$ \\
\hline & EN2: Resource consumption & $\begin{array}{l}\text { The building envelope material and design must minimize resources } \\
\text { used during construction such as water, chemicals, sealants, etc. }\end{array}$ \\
\hline & EN3: Waste generation & $\begin{array}{l}\text { Waste generation especially air pollution and wastewater should be } \\
\text { minimized to reduce the impacts on the surrounding environments. }\end{array}$ \\
\hline Economic & $\begin{array}{l}\text { EC1: Initial costs } \\
\text { EC2: Long-term burdens }\end{array}$ & $\begin{array}{l}\text { The project budget must be minimized. } \\
\text { The design must minimize long-term burdens particularly } \\
\text { repairing and replacing costs. }\end{array}$ \\
\hline \multirow{5}{*}{ Social } & SC1: Energy efficiency & $\begin{array}{l}\text { Energy efficiency of the design must be maximized to achieve } \\
\text { high energy efficiency and occupant comfort. }\end{array}$ \\
\hline & SC2: Appearance demands & $\begin{array}{l}\text { Appearance demands of the design must be maximized and the } \\
\text { design must be modern and represent positive image. }\end{array}$ \\
\hline & $\begin{array}{l}\text { SC3: Health, safety and } \\
\text { security of occupants }\end{array}$ & $\begin{array}{l}\text { Health, safety and security of the occupants and society must } \\
\text { be maximized. }\end{array}$ \\
\hline & $\begin{array}{l}\text { SC4: Weather } \\
\text { protection performance }\end{array}$ & $\begin{array}{l}\text { The design should minimize negative influence from adverse } \\
\text { weather during occupation phase. }\end{array}$ \\
\hline & SC6: Visual performance & $\begin{array}{l}\text { Visual performance of the design should be maximized to achieve high } \\
\text { occupant comfort. }\end{array}$ \\
\hline \multirow{3}{*}{ Buildability } & $\begin{array}{l}\mathrm{BC} 1 \text { : Health and safety } \\
\text { of workers }\end{array}$ & $\begin{array}{l}\text { The building envelope material and design must maximize workers' } \\
\text { health and safety during construction. }\end{array}$ \\
\hline & $\begin{array}{l}\text { BC4: Material handling } \\
\text { BC5: Ease in construction }\end{array}$ & $\begin{array}{l}\text { The building envelope material and design must maximize ease in } \\
\text { off-site and on-site handling methods. }\end{array}$ \\
\hline & with respect to time & $\begin{array}{l}\text { The building envelope material and design must maximize } \\
\text { ease in construction within a time given. }\end{array}$ \\
\hline
\end{tabular}

Step 1: Considering the information given in Table 2, the team entered relevant information of the project as shown in the screenshot in Figure 3 and set up the fuzzy linguistic terms. 


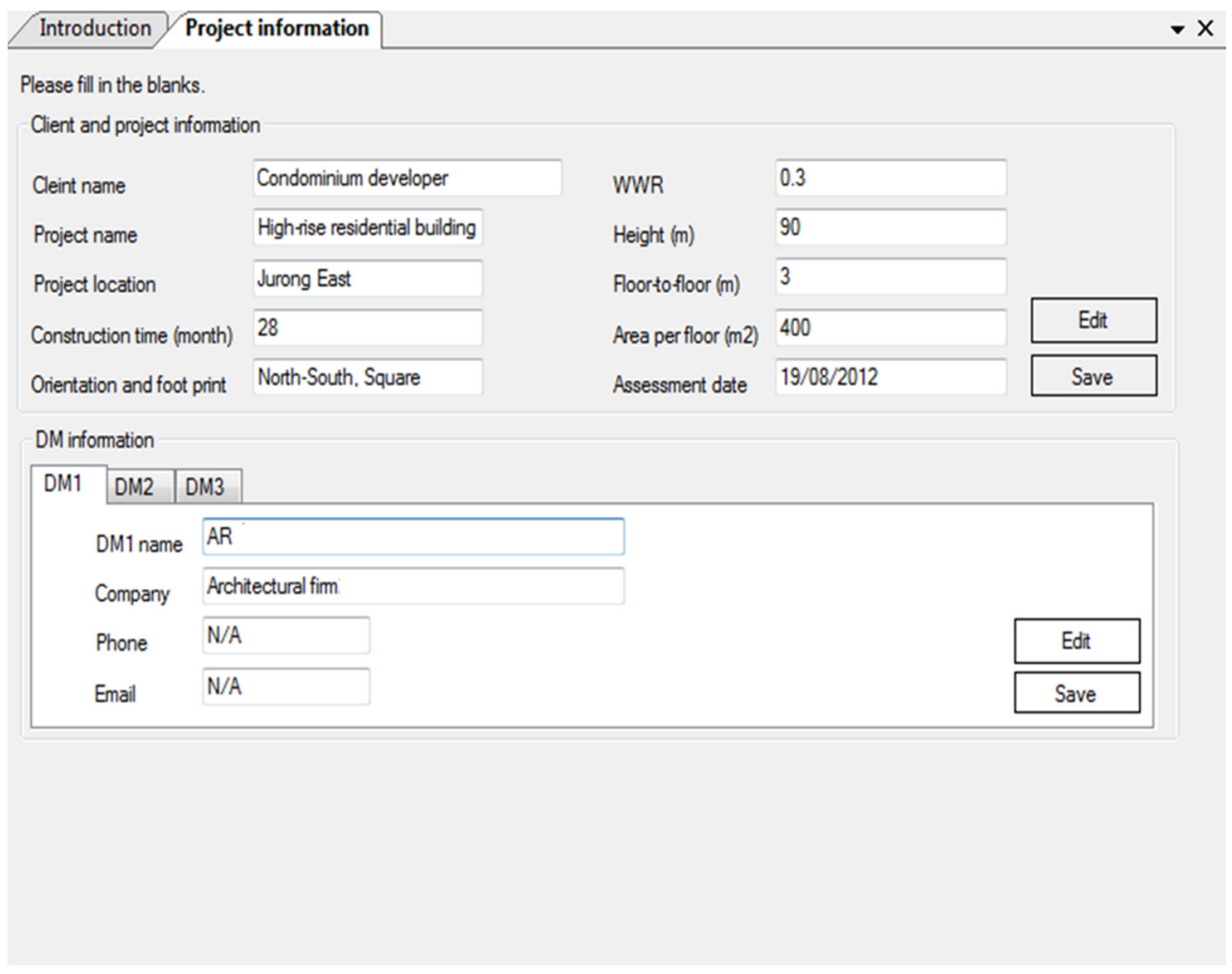

Figure 3. Project information.

Step 2: The design team inserted the sustainability and buildability criteria as given in Table 3 as the basic requirements of the project.

Step 3: The DMs determined the tradeoffs between the selected criteria by assigning their importance weights. Figure 4 shows the screenshot for rating the importance weights of the "EN1" Energy consumption, "EN2" Waste consumption, and "EN3" Resource consumption.

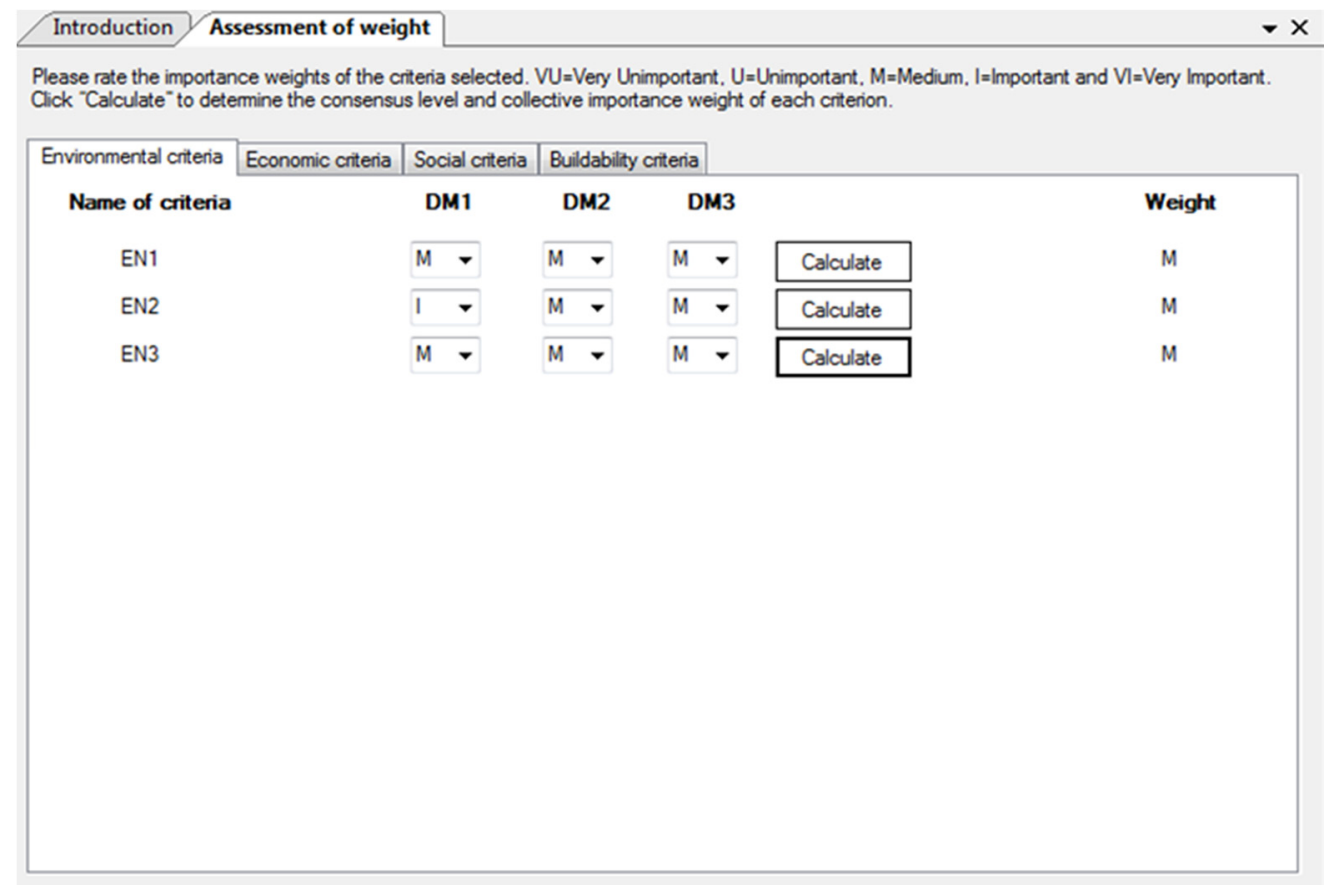

Figure 4. Assessment of the importance weights for all the criteria for the case study two. 
Step 4: Based on the preferred external wall materials given in the Table 2, the team formed three alternatives for the assessment as shown in Figure 5. Alternative 1 consists of "BL1" Concrete block wall, "WG4" Double layer low-E glazing window, and the "SD1" Horizontal shading device. The team replaced the external wall of the Alternative 1 with "CB1" Claybrick to develop the Alternative 2. The Alternative 3 was then established. It comprises "PC1" Precast wall, "WG4" Double layer low-E glazing window, and "SD2" Horizontal shading device integrated with the precast panel.

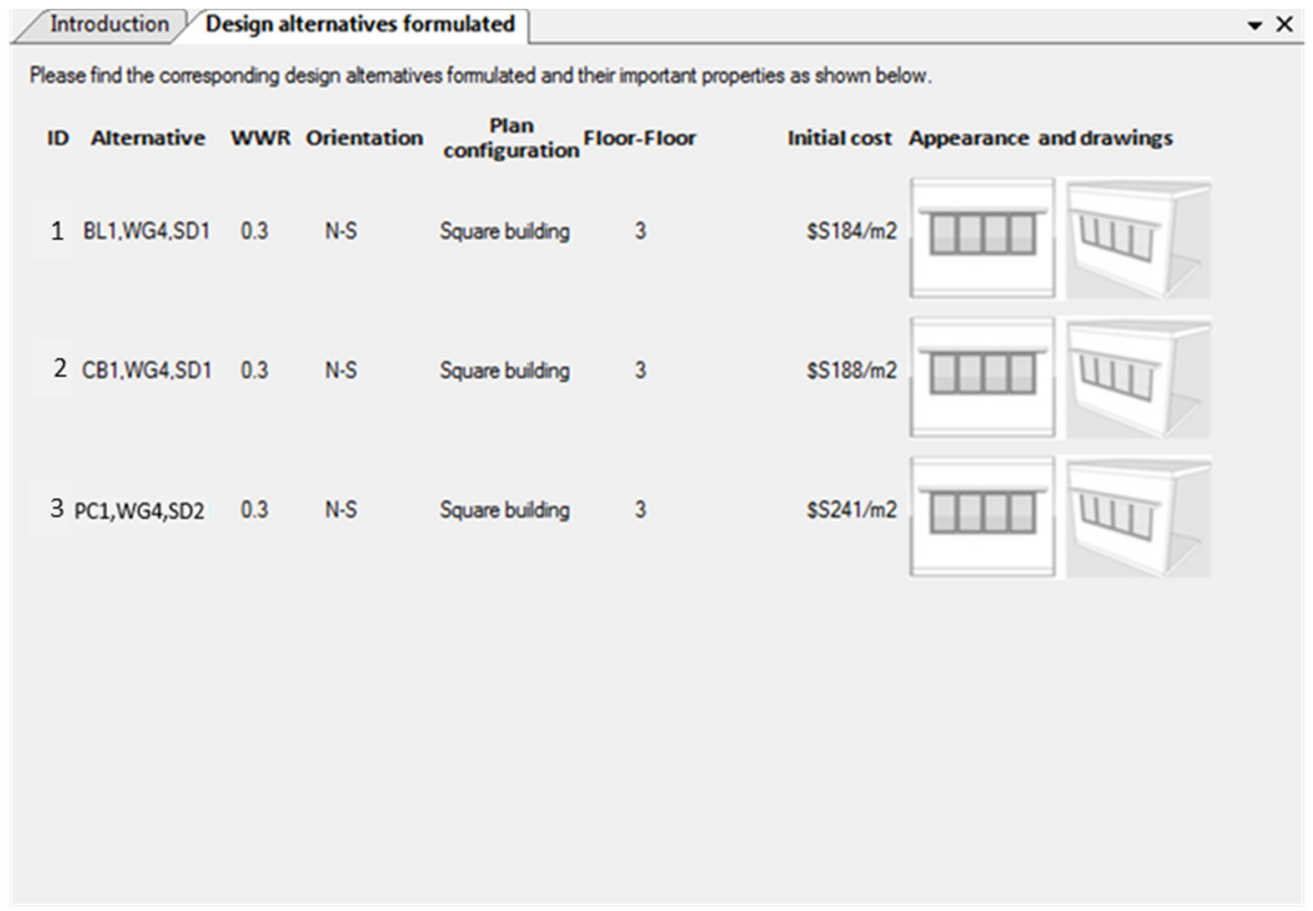

Figure 5. Building envelope design alternatives.

Step 5: The DMs rated the performance satisfactions of the three design alternatives formulated with respect to the criteria. The screenshot given in Figure 6 reflects rating of the performance satisfactions of the design alternatives with respect to the "SC4" Weather protection performance.

The screenshot of the tool given in Figure 7 provides a summary of the importance weights of the criteria, performance satisfactions of the design alternatives, and their corresponding SBI. As can be seen in this figure, the ranking from the highest to lowest SBI of the design alternatives is the Alternative "3" PC1WG4SD2, "1" BL1WG4SD1 and "2" CB1WG4SD1. Comparing between the Alternative "2" CB1WG4SD1 and "1" BL1WG4SD1, the type of the external wall is the only difference between these two alternatives. However, the Alternative "2" BL1WG4SD1 received higher performance satisfaction with respect to a number of criteria particularly the "EN1" Energy consumption and "EN2" Resource consumption. This could be because the DMs viewed that the concrete blockwall requires less energy and resource consumption during construction as compared to the clay brickwall.

Furthermore, when it comes to comparison between the Alternative "3" PC1WG4SD2 and "2" BL1WG4SD1, there are two main differences which are the type of the external wall and type of the shading device. In brief, Alternative 3 using the precast concrete wall received higher performance satisfactions than Alternative 2 incorporated with the concrete blockwall with respect to the "EN1" Energy consumption, "EN2" Resource consumption, "SC4" Weather protection, and "BC6" Community 
disturbance. Similarly, based on its shading device, Alternative 3 obtained higher performance satisfaction with respect to a number of criteria such as the "EN1" Energy consumption, "EN2" Resource consumption, and "EN3" Waste generation. This was because the shading device of Alternative 1 would be integrated with the precast concrete panel by a manufacturer, while that of Alternative 2 would be installed on site. These collectively contributed to a higher SBI of the design Alternative 3 PC1WG4SD2. As such, the design team adopted this design alternative as a base case for further development of the detailed designs of this project. The design team took approximately two hours and a half to complete this case study exercise.

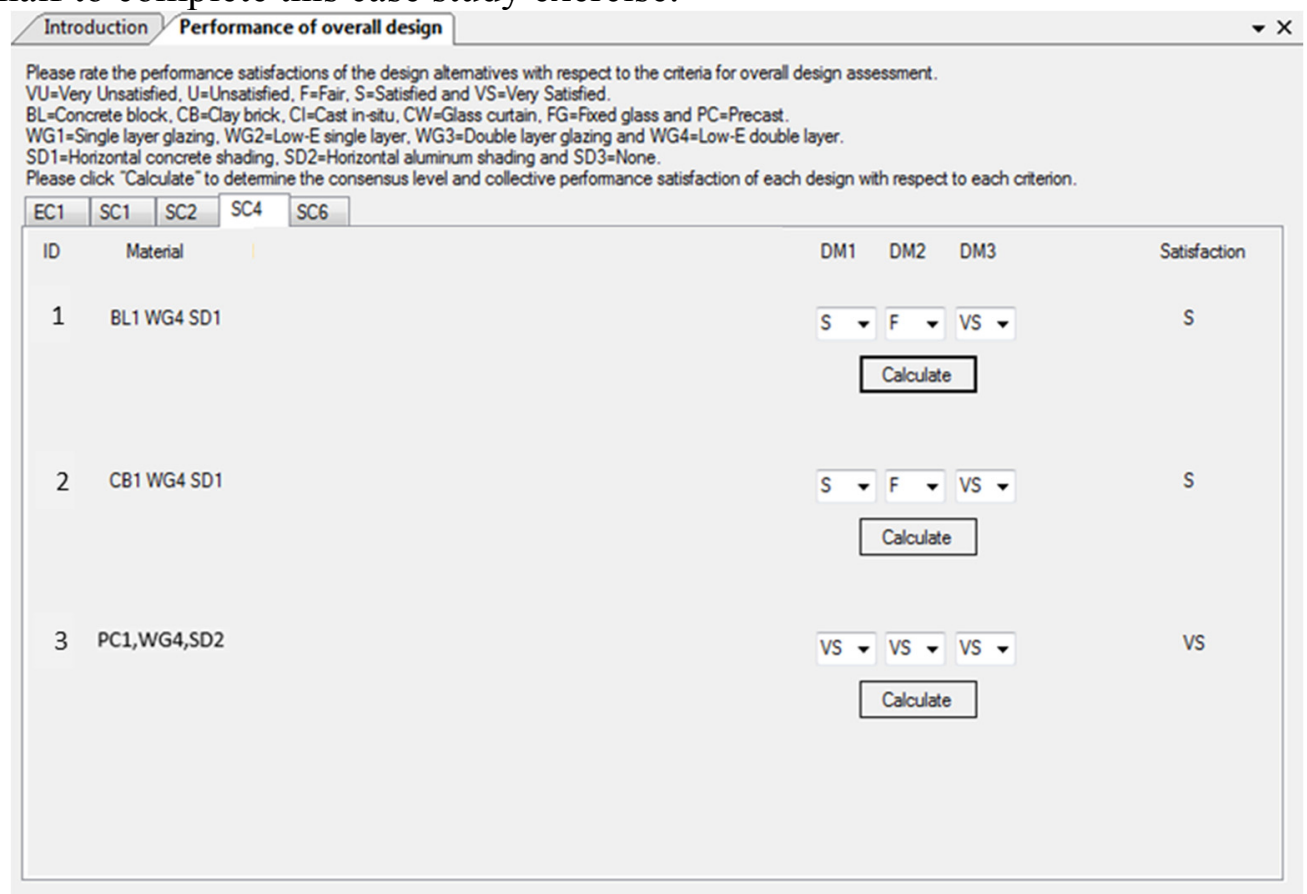

Figure 6. Assessment of the performance satisfaction of the design alternatives.

\begin{tabular}{|c|c|c|c|c|c|}
\hline Introduction Summary table & & & & & $-x$ \\
\hline \multicolumn{6}{|c|}{ 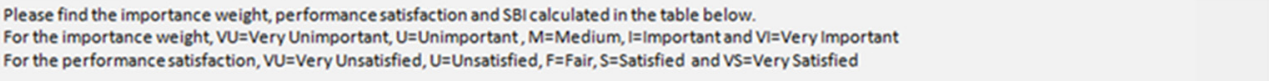 } \\
\hline \multicolumn{5}{|c|}{ Performance satisfaction } & \\
\hline Criteria & Importance weight & Alt 1 & Alt 2 & Alt 3 & \\
\hline EN1:Energy consumption & M & s & $\mathbf{F}$ & vs & \\
\hline EN2:Resource consumption & M & s & $\mathbf{F}$ & vs & \\
\hline EN3:Waste generation & M & s & $\mathbf{F}$ & s & \\
\hline EC1:Initial costs & Vl & s & s & $\mathbf{F}$ & \\
\hline EC2:Long-term burdens & 1 & $\mathbf{F}$ & $\mathbf{F}$ & s & \\
\hline SC1:Energy efficiency & 1 & vs & vs & vs & \\
\hline SC2:Appearance demands & VI & F & $\mathbf{F}$ & $\mathbf{F}$ & \\
\hline SC3: Health, safety and security of occupants and society & VI & s & s & s & \\
\hline $\mathrm{SC} 4:$ Weather protection performance & vl & s & s & vs & \\
\hline SC6:Visual performance & I & F & $\mathbf{F}$ & $\mathbf{F}$ & \\
\hline BC1: Health and safety of worker & vi & $F$ & $\mathbf{F}$ & s & \\
\hline BCS: Ease in construction with respect to time & Vl & s & s & s & \\
\hline \multirow[t]{3}{*}{ BC6:Community disturbance } & VI & s & $\mathbf{F}$ & vs & \\
\hline & SBI & 0.655 & 0.598 & 0.754 & \\
\hline & Linguisticterm & $s$ & $\mathbf{F}$ & s & \\
\hline
\end{tabular}

Figure 7. Summary of the design solutions. 


\section{Discussions}

After the team completed the assignment, qualitative data analysis was applied to analyze the perspectives of the DMs collected through the interviews. From this analysis, the DMs presented the positive attitude that the fuzzy QFD tool provided a more structured decision making process based on both the decision making steps and fuzzy operations for assessing the building envelopes. This decision making process guided the DMs to deliberately go through each decision making step, and this increased efficiency and consistency in making the decisions. The tool also provided the DMs with more flexibility to instantly select different criteria from the provided list of the sustainability and buildability criteria to deal with specific project requirements, supporting the team to analyze the project criteria with respect to various alternatives in a limited timeframe. These as a whole significantly facilitated the DMs to discuss and sort out tradeoffs among the criteria in the forms of the importance weights and performance satisfactions. Success in management of such tradeoffs heavily lies in these discussions because the discussions gave the DMs a platform to fine-tune their perspectives including sharing and listening to each other's opinions.

The DMs further highlighted that the fuzzy linguistic terms well captured imprecise perspectives of the designers, and these were incorporated into the assessment in a systematic manner to determine the SBI of each alternative. This made the SBI representing a level of the sustainability and buildability of the design alternatives a good indicator for selection of a more sustainable and buildable building envelope design. Nevertheless, the DMs pointed out a few suggestions for future improvement of the tool. The first comment is that the efficiency of the assessment would be further improved if additional guidelines such as guided importance weights and guided performance satisfactions could be suggested by the tool. Such guidelines possibly stored in a Knowledge Management System (KMS) would help the DMs fasten their discussions and effectively arrive at agreed decisions [44]. Another point is that the DMs perceived that the tool seems to be a bit too complicated. It seems to be hard to update the knowledge of the tool, and the assessment appears to heavily rely (but understandably) on the team facilitator. Furthermore, in some circumstances, as there could be disagreements among DMs, a more systematic discussion procedure such as a consensus scheme should be embedded into the tool to mitigate this issue [45]. Future studies may consider these suggestions when developing their decision support tools. Although a limitation of this study is that the study engaged only one case study to proof the development of the tool, the study brings out key insights that could shed some lights on various possible scenarios. As such, the next phase is to expand the research scale to cover a larger number of the building design teams including use of actual building envelope design projects.

\section{Conclusions}

This study builds the fuzzy QFD tool to assist the building design to manage the tradeoffs among the sustainability and buildability criteria when assessing the building envelope materials and designs in the early design stage. This tool is modeled through the integration between the fuzzy multicriteria decision making method and QFD approach. The tool is tested in the case study of the building design team to determine the building envelope system for the representative project. The results from the interviews show that the tool has the potential to effectively strike a balance between the tradeoffs 
among the criteria. In brief, the fuzzy QFD tool helps the designers to simultaneously consider the sustainability and buildability criteria, and effectively assign the importance weights of the criteria and performance satisfactions of the designs. At the same time, the structured decision making process improves communication and integration among the designers. This helps generate effective and consistent decisions including more sustainable and buildable designs.

The tool developed in this study not only benefits the design team to manage the tradeoffs when assessing the building envelope materials and design in the early design stage but also expands the body of academic knowledge, as the study presents the advanced approach to combine the fuzzy multicriteria decision making method with QFD approach. However, the limitation of this study is that there is only one hypothetical case study used to prove the development of the concept for the decision-making tool. Future research is therefore recommended to apply the findings of this study to develop and further improve decision support tools to deal with other related research problems. This can include further investigations of the impacts of the fuzzy QFD tool on a larger research scale.

\section{Acknowledgements}

The authors gratefully acknowledge the suggestions and comments from three anonymous reviewers. Their recommendations have been most helpful.

\section{Author Contributions}

The first author was responsible for carrying out development of the tool and putting together the results/analysis. The second author provided guidance/direction on the research, as well as proof reading and editing of the paper.

\section{Conflicts of Interest}

The authors declare no conflict of interest.

\section{References}

1. Kibert, C.J. Sustainable Construction: Green Building and Delivery, 2nd ed.; John Wiley and Son, Inc.: New Jersey, NJ, USA, 2008.

2. Chew, Y.L. Construction Technology for Tall Buildings; World Scientific Publishing: Singapore, 2009.

3. Chua, K.J.; Chou, S.K. Evaluating the performance of shading devices and glazing types to promote energy efficiency of residential buildings. Build. Simul. 2010, 3, 181-194.

4. Bansal, P. Evolving sustainably: A longitudinal study of corporate sustainable development. Strat. Manag. J. 2005, 26, 197-218.

5. Low, S.P.; Liu, J.Y.; Oh, K.H. Influence of total building performance, spatial and acoustic concepts on buildability scores of facilities. Facilities 2008, 26, 85-104.

6. Building and Construction Authority (BCA). Code for Environmental Sustainability of Building, 3rd ed.; BCA: Singapore, 2012. Available online: http://www.bca.gov.sg/Envsuslegislation/ Environmental_sustainability_legislation.html (accessed on 4 March 2015). 
7. Building and Construction Authority (BCA). Code of Practice on Buildability; BCA: Singapore, 2013. Available online: http:/www.bca.gov.sg/BuildableDesign/others/copbdsep2013.pdf (accessed on 2 March 2015).

8. Singhaputtangkul, N.; Low, S.P.; Teo, A.L. Integrating sustainability and buildability requirements in building envelopes. Facilities 2011, 29, 255-267.

9. Singhaputtangkul, N.; Low, S.P.; Teo, A.L.; Hwang, B.G. Criteria for architects and engineers to achieve sustainability and buildability in building envelope designs. J. Manag. Eng. 2014, 30, 236-245.

10. Yang, Y.Q.; Wang, S.Q.; Dulaimi, M.; Low, S.P. A fuzzy quality function deployment system for buildable design decision-makings. Autom. Constr. 2003, 12, 381-393.

11. Ahn, Y.; Pearce, A. Green construction: Contractor experiences, expectations, and perceptions. J. Green Build. 2007, 2, 106-122.

12. Lapinski, A.; Horman, M.; Riley, D. Lean processes for sustainable project delivery. J. Constr. Eng. Manag. 2006, 132, 1083-1091.

13. Wong, W.H.; Lam, T.L.; Chan, H.W.; Wong, K.W. Factors affecting buildability of building designs. Can. J. Civil Eng. 2006, 33, 795-806.

14. Lam, P.T.I.; Chan, A.P.C.; Wong, F.W.K.; Wong, F.W.H. Constructability rankings of construction systems based on the analytical hierarchy process. J. Arch. Eng. 2007, 13, 36-43.

15. Low, S.P.; Abeyegoonasekera, B. Buildability in design and construction through ISO 9000 quality management systems: Concepts and survey findings. Arch. Sci. Rev. 2001, 44, 355-366.

16. Fox, S.; Marsh, L.; Cockerham, G. Constructability runs les: Guidelines for successful application to bespoke buildings. Constr. Manag. Econ. 2002, 20, 689-696.

17. Nima, M.A.; Abdui-Kadir, M.R.; Jaafar, M.S.; Alghulami, R.G. Constructability implementation: A survey of the Malaysian construction industry. Constr. Manag. Econ. 2002, 19, 819-829.

18. Bryan, T. Construction Technology: Analysis and Choice; Blackwell Publishing Ltd.: West Sussex, UK, 2010.

19. Scheuer, C.; Keoleian, G.A.; Reppe, P. Life cycle energy and environmental performance of a new university building: Modeling challenges and design implications. Energy Build. 2003, 35, 1049-1064.

20. Chen, Y.; Okudan, G.E.; Riley, D.R. Sustainable performance criteria for construction method selection in concrete buildings. Autom. Constr. 2010, 19, 235-244.

21. Tsai, W.H.; Lin, S.J.; Liu, J.Y.; Lin, W.R.; Lee, K.C. Incorporating life cycle assessments into building project decision-making: An energy consumption and $\mathrm{CO}_{2}$ emission perspective. Energy 2011, 36, 3022-3029.

22. Jaillon, L.; Poon, C.S. Sustainable construction aspects of using prefabrication in dense urban environment: A Hong Kong case study. Constr. Manag. Econ. 2008, 26, 953-966.

23. Wang, W.; Rivard, H.; Zmeureanu, R. Floor shape optimization for green building design. Adv. Eng. Inf. 2006, 20, 363-378.

24. Das, S.; Chew, M.Y.L.; Poh, K.L. Multi-criteria decision analysis in building maintainability using analytical hierarchy process. Constr. Manag. Econ. 2010, 28, 1043-1056. 
25. Lacasse, M.A.; Vanier, D.J.; Kyle, B.R. Towards Integration of Service Life and Asset Management Tools for Building Envelope Systems. In Proceedings of the 7th Conference on Building Science and Technology: Durability of Buildings Design, Maintenance, Codes and Practice, Toronto, Canada, 20-21 March 1997; pp. 153-167.

26. Kneifel, J. Life-cycle carbon and cost analysis of energy efficiency measures in new commercial buildings. Energy Build. 2010, 42, 333-340.

27. Kaklauskas, A.; Zavadskas, E.K.; Raslanas, S.; Ginevicius, R.; Komka, A.; Malinauskas, P. Selection of low-e windows in retrofit of public buildings by applying multiple criteria method COPRAS: A Lithuanian case. Energy Build. 2006, 38, 454-462.

28. Brock, L. Designing the Exterior Wall: An Architectural Guide to The Vertical Envelope; John Wiley and Sons, Inc.: New Jersey, NJ, USA, 2005

29. Yu, C.W.F.; Kim, J.T. Building pathology, investigation of sick buildings: VOC emissions. Indoor Built Environ. 2010, 19, 30-39.

30. Low, S.P.; Liu, J.Y.; Wong, H.L. Relationship between buildability, indoor air quality and visual performance. Struc. Surv. 2008, 26, 38-54.

31. Nielsen, T.R. Optimization of Buildings with respect to Energy and Indoor Environment. Ph.D. Thesis, The Technical University of Denmark, Copenhagen, Denmark, 2002.

32. Hinze, J.; Devenport, J.; Giang, G. Analysis of construction worker injuries that do not result in lost time. J. Constr. Eng. Manag. 2006, 132, 321-326.

33. Gould, F.E. Managing the Construction Process: Estimating, Scheduling, and Project Control, 3rd ed.; Pearson Prentice Hall: New Jersey, NJ, USA, 2005.

34. Vrijhoef, R.; Koskela, L. The four roles of supply chain management in construction. Eur. J. Purch. Supply Manag. 2000, 6, 169-178.

35. Dikmen, I.; Birgonul, M.T.; Kiziltas, S. Strategic use of quality function deployment (QFD) in the construction industry. Build. Environ. 2005, 40, 245-255.

36. Xie, M.; Tan, K.C.; Goh, T.N. Advanced QFD Applications; ASQ Quality Press: Milwaukee, WI, USA, 2003.

37. Low, S.P.; Yeap, L. Quality function deployment in design/build projects. J. Arch. Eng. 2001, 7, 30-39.

38. Reilly, C. Making Hard Decisions with Decision Tools; Duxbury Thomson Learning: Pacific Grove, CA, USA, 2001.

39. Lam, K.C.; Ran, T.; Lam, M.C.K. A material supplier selection model for property developers using fuzzy principal component analysis. Autom. Constr. 2010, 19, 608-618.

40. Zadeh, L.A. Fuzzy sets. Inf. Control 1965, 8, 338-353.

41. Bayrak, M.Y.; Çelebi, N.; Takin, H. A fuzzy approach method for supplier selection. Prod. Plan. Control 2007, 18, 54-63.

42. Yin, R.K. Case Study Research: Design and Methods, 4th ed.; Sage: Thousand Oaks, CA, USA, 2009.

43. Creswell, J.W. Research Design Qualitative, Quantitative and Mixed Methods Approaches, 2nd ed.; Sage Publications: Thousand Oaks, CA, USA, 2003.

44. Turban, E.; Aronson, J.E.; Laing, T.P.; Sharda, R. Decision Support and Business Intelligence Systems, 8th ed.; Prentice Hall: New Jersey, NJ, USA, 2007. 
45. Elbarkouky, M.; Fayek, A. Fuzzy similarity consensus model for early alignment of construction project teams on the extent of their roles and responsibilities. J. Constr. Eng. Manag. 2011, 137, 432-440.

(C) 2015 by the authors; licensee MDPI, Basel, Switzerland. This article is an open access article distributed under the terms and conditions of the Creative Commons Attribution license (http://creativecommons.org/licenses/by/4.0/). 